\title{
ABCS Health Sciences: segundo checkpoint
}

\author{
Ricardo Peres do Souto ${ }^{1}$
}

Editor responsável - E-mail: ricardo.souto@fmabc.br

DOI: http://dx.doi.org/10.7322/abcshs.v43i3.1227

Em 2013, ano em que a revista adotou o nome ABCS Health Sciences, fiz o primeiro balanço das atividades com o novo título ${ }^{1}$. Passados seis anos é chegada a hora de uma reavaliação.

Nesse período verificou-se crescimento da revista em vários aspectos (Tabela 1). Houve um importante aumento da procura da revista por pesquisadores para a publicação de seus estudos científicos. Enquanto em 2013 a revista recebeu 55 submissões, em 2017 esse número subiu para 113. Em outras palavras, em cinco anos o recebimento de manuscritos para publicação praticamente dobrou. Em 2018 a tendência de crescimento das submissões aparentemente se mantém. Recebemos até o momento 111 manuscritos, o que permite projetar cerca de 120 submissões até o fim do ano. Esse aumento ocorreu principalmente devido ao maior aporte de manuscritos enviados por pesquisadores de instituições diferentes da Faculdade de Medicina do ABC (FMABC), onde se encontra a sede da revista. Os artigos de pesquisadores externos à FMABC sempre foram maioria na ABCS Health Sciences e continuam crescendo continuamente em ritmo maior que as submissões da FMABC. O maior afluxo de manuscritos recebidos permitiu ao corpo editorial maior exigência na aprovação dos artigos. Entre os manuscritos submetidos em 2013, aproximadamente um a cada dois eram aprovados. Esse índice de aprovação se reduziu para um a cada três em 2017.

Em 2013, os dois principais projetos para a revista eram a utilização da plataforma SEER/OJS (Sistema Eletrônico de Editoração de Revistas/Open Journal System) para divulgação online e a atribuição de DOI (Digital Identifier Object) aos artigos. Hoje, essas antigas metas fazem parte do cotidiano da revista. Além disso,

Tabela 1: Evolução de índices da ABCS Health Sciences entre 2013 e 2017.

\begin{tabular}{|l|c|c|c|}
\hline & 2013 & 2017 & Variação \\
\hline Total de submissões & 55 & 113 & $+105 \%$ \\
\hline Taxa de aprovação & $56 \%$ & $35 \%$ & - \\
\hline Número de submissões externas à FMABC & 35 & 103 & $+194 \%$ \\
\hline Proporção de submissões externas à FMABC & $63 \%$ & $91 \%$ & - \\
\hline
\end{tabular}

houve grande progresso da revista na adoção de boas práticas de política editorial:

- segue os preceitos do Movimento Acesso Aberto (Budapeste Open Access Iniciative) ${ }^{2}$;

- tem política editorial no diretório público Diadorim mantido pelo IBICT (Instituto Brasileiro de Informação em Ciência e Tecnologia);

- é preservada digitalmente pela Rede Cariniana do IBICT;

- faz verificação antiplágio de todas as submissões com serviço iThenticate.

Ainda nesse período a revista foi incluída no DOAJ (Directory of Open Access Journals), Index Copernicus e REDIB (Red Iberoamericana de Innovación y Conocimiento Científico). Outras indexações foram solicitadas e os processos se encontram em andamento.

Esses resultados são fruto do esforço integrado do corpo editorial que conta com os Profs. Fernando Adami, Rodrigo Daminello e Simone Castillo da FMABC e os Profs. Francisco Vasconcelos (UFSC), Guilherme Malafaia (IFGoiano), Márcia Blake (UFPA) e Vitor Valenti (UNESP). Agradecemos muito a participação da equipe técnica do NEPAS (Ana Ivone Costa e Erica Sato) e a colaboração da equipe técnica da FMABC/ FUABC (Camila Queiroz, Eduardo Nascimento, Fernando Valini, Francisco Winter, Klébson Carvalho, Laércio Paiva e Regiane Meira).

Os desafios para o futuro da revista ainda são enormes. O maior deles é ampliar o número de indexações em bases de dados internacionais. A ABCS Health Sciences ainda apresenta um caráter predominantemente nacional. Apenas pequena fração dos artigos é publicada em inglês: em 2017 foram 6\%. A revista não recebe submissões originadas de fora do Brasil. Outros objetivos a serem perseguidos incluem: implantar o sistema online da plataforma SEER para submissão de artigos; reduzir o tempo de avaliação dos manuscritos (a média de tempo da submissão à aprovação é de 5 meses); melhorar o portal internet da revista acrescendo o serviço Cited-by do Crossref e a publicação de artigos imediatamente após a aprovação em um fascículo ahead of print. Essas são as diretrizes do plano de desenvolvimento da ABCS Health Sciences para os próximos anos.

\section{REFERÊNCIAS}

1. Souto, RP. O primeiro ano da revista ABCS Health Sciences. ABCS Health Sci. 2013;38(3):123.

http://dx.doi.org/10.7322/abcshs.v38i3.15
2. Budapest Open Access Initiative. Disponível em: https:// www.budapestopenaccessinitiative.org/. Acesso em: 30 nov. 2018. 